\title{
Benign biliary strictures: utility of novel biodegradable biliary stents in surgically altered anatomy
}

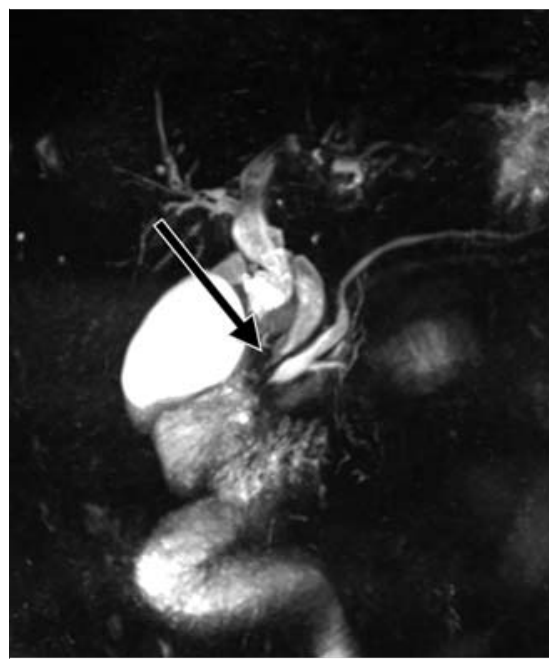

Fig. 1 Distal common bile duct stricture (arrow).

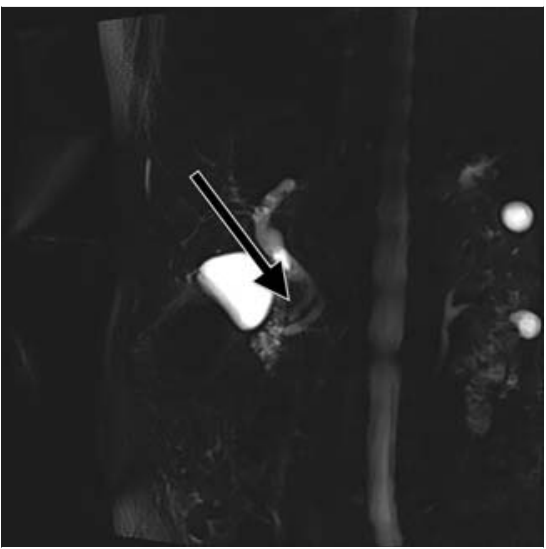

- Fig. 2 Resolved common bile duct stricture (arrow).

Benign biliary strictures are traditionally managed by placement of either plastic stents or, more recently, fully covered self-expandable metal stents (FCSEMs) $[1,2]$. Though effective, plastic stents need replacement every 2-3 months, whereas FCSEMs need removal in 6-9 months, both requiring repeat endoscopic retrograde cholangiopancreatography (ERCP). Surgically altered anatomy makes ERCP challenging, and these

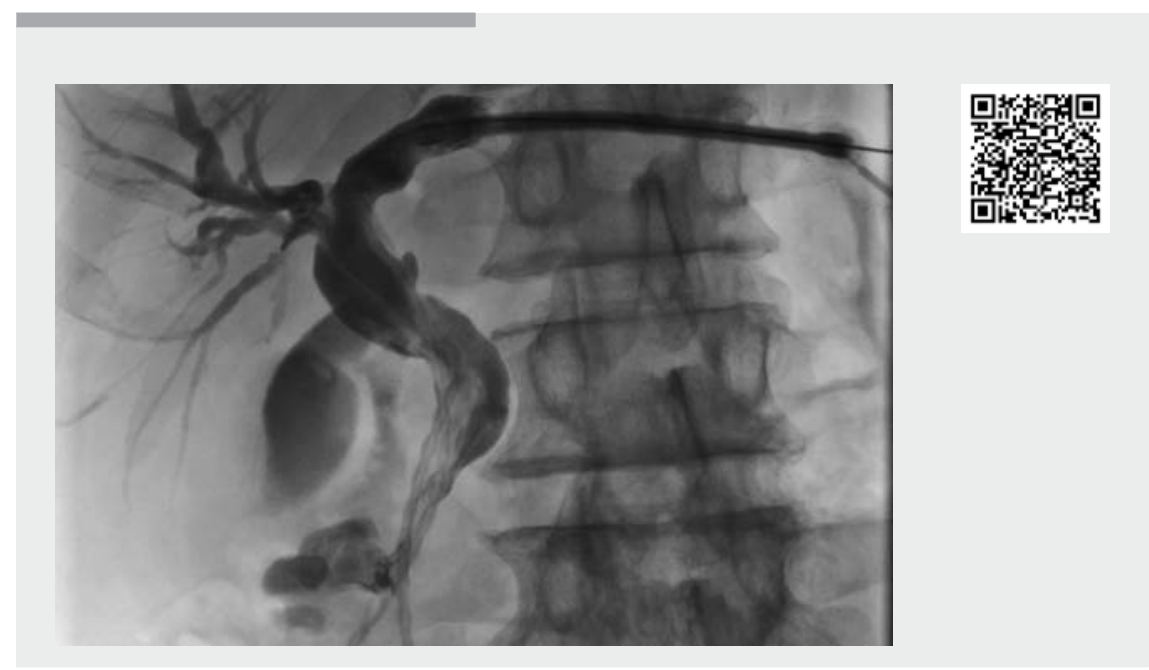

Video 1 Common bile duct stricture and placement of biodegradable stents.

patients require either a percutaneous approach or balloon-assisted endoscopy with specially designed biliary instruments.

An 80-year-old man presented with cholangitis. He had previously undergone gastrectomy with Roux-en-Y gastrojejunostomy for gastric cancer. Imaging revealed common bile duct (CBD) stones and a distal CBD stricture ( $\triangleright$ Fig. 1). As conventional ERCP was not possible, he underwent percutaneous transhepatic biliary drainage, radiological sphincteroplasty, and stone removal. However, he continued to have recurrent cholangitis when the external drain was clamped, thus requiring long-term external drainage. Following multidisciplinary team discussion, diagnostic percutaneous cholangioscopy followed by placement of biodegradable stents was planned.

An initial cholangiogram via the indwelling biliary drain revealed a focal distal CBD stricture ( $\vee$ Video 1 ). The biliary drain was exchanged for an 8-Fr sheath, followed by the insertion of two $180 \mathrm{~cm}$ wires. The cholangioscope was passed over one of the wires to visualize the stricture, which looked benign. SpyBite (Boston Scientific, Marlborough, Massachusetts, USA) biopsies were taken. Two 8- $\mathrm{Fr}$ biodegradable stents were then placed. The biopsies did not show any evidence of malignancy and liver biochemistry returned to normal. Magnetic resonance imaging after 6 months showed resolution of the stricture with some degraded stent particles. Another scan after 3 months revealed a clear duct ( $\triangleright$ Fig. 2).

Biodegradable stents are a novel alternative to conventional stents in highly selected cases, and can be placed both endoscopically or percutaneously. They are made of polydioxanone and have been licensed for use in the esophagus and lower gastrointestinal tract $[3,4]$. They degrade via hydrolysis with variable degradation times: slow (11 weeks), medium (20 days), and fast (12 days). They have a helicoidal shape to facilitate bile flow on the outer surface while supporting ductal flow. There have been no significant complications other than a few reported cases of cholangitis due to degraded stent particles. 
This case demonstrates the importance of considering novel biodegradable stents in cases of biliary obstruction with altered surgical anatomy. Biodegradable stents offer the improved patency of metal stents, but obviate the need for repeat, complex interventions required to remove or exchange them.

Endoscopy_UCTN_Code_TTT_1AR_2AZ

\section{Competing interests}

The authors declare that they have no conflict of interest.

The authors

Sreelakshmi Kotha ${ }^{1}$, Philip Berry ${ }^{1}$, Usman Raja $^{2}$, Terry Wong ${ }^{1}$

1 Department of Gastroenterology, Guy's and St Thomas' Foundation Trust, London, United Kingdom

2 Department of Interventional Radiology, Guy's and St Thomas' Hospital, London, United Kingdom
Corresponding author

\section{Sreelakshmi Kotha, MD}

Department of Gastroenterology, Guy's and St Thomas' Hospital, Westminster Bridge Road, Lambeth, London SE1 7EH, United Kingdom

Fax: +44-207-1887188

sreelakshmi_kotha@yahoo.com

\section{References}

[1] Draganov P, Hoffman B, Marsh W et al. Longterm outcome in patients with benign biliary strictures treated endoscopically with multiple stents. Gastrointest Endosc 2002; 55: 680-686

[2] Dumonceau J-M, Tringali A, Blero D. European Society of Gastrointestinal Endoscopy et al. Biliary stenting: indications, choice of stents and results. Endoscopy 2012; 44 277-298

[3] Griffiths EA, Gregory C], Pursnani KG et al. The use of biodegradable (SX-ELLA) oesophageal stents to treat dysphagia due to benign and malignant oesophageal disease. Surg Endosc 2012; 26: 2367-2375

[4] Janik V, Horak L, Hnanicek J et al. Biodegradable polydioxanone stents: a new option for therapy-resistant anastomotic strictures of the colon. Eur Radiol 2011; 21:

1956-1961
Bibliography

Endoscopy 2021; 53: E281-E282

DOI 10.1055/a-1261-2800

ISSN 0013-726X

published online 1.10 .2020

(c) 2020. Thieme. All rights reserved.

Georg Thieme Verlag KG, Rüdigerstraße 14,

70469 Stuttgart, Germany

\section{ENDOSCOPY E-VIDEOS}

https://eref.thieme.de/e-videos

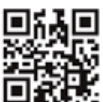

Endoscopy E-Videos is a free access online section, reporting on interesting cases and new techniques in gastroenterological endoscopy. All papers include a high quality video and all contributions are freely accessible online.

This section has its own submission website at https://mc.manuscriptcentral.com/e-videos 